\title{
Self-reported health problems of Slovak adolescents
}

\author{
Andrea Geckova, Jolanda Tuinstra, Marcel Pudelsky, Maria Kovarova, \\ Jitse P. van Dijk, Johan W. Groothoff and Doeke Post
}

\begin{abstract}
This paper describes self-reported health problems among 2616 Slovak adolescents ( $52 \cdot 4 \%$ boys, $47 \cdot 6 \%$ girls). Adolescents consider their health as very good in general. They often feel 'vital', and rarely feel depressed or irritated. However, the psychological health of more than $20 \%$ of the boys and $40 \%$ of the girls was unsatisfactory. Furthermore, a sizeable number suffered from separate physical complaints, chronic diseases or used medical services. Findings are more unfavourable for girls in comparison with boys. Our findings indicate that adolescence is not such a healthy period in human life as is often considered. The Slovak Republic, a Central European country, does not differ in this respect from Western European countries.
\end{abstract}

(C) 2001 The Association for Professionals in Services for Adolescents

\section{Introduction}

Health is one of the most valuable aspects of human life. One of the ways of protecting it is to investigate and collect information about it during a period in life. Adolescence in particular seems to be a very important period, because it is the time when people are looking for, experimenting with and also establishing, the life style, attitudes, concepts, beliefs and habits which may have long-term influences on their health. Some unfavourable health processes can be reversible at this time. Surveys of adolescents' health are also interesting because there is disagreement among findings in two areas: those obtained by commonly used health indicators, such as mortality and morbidity and those obtained by self-reported health indicators, such as self-rated health, self-reported questionnaires of psychological health, physical health complaints, long-standing diseases or medical consumption. According to the former, adolescence seems to be a very healthy period. However, research based on self-reported health indicators shows a considerably high prevalence of health problems. This indicates that there are differences between the adolescents' own perception of their health and results of epidemiological studies based on mortality and morbidity.

Health is more than just a mortality or morbidity rate. Without doubt, the concept of health includes also feelings, worries, and the perceptions of adolescents related to health. For this reason, self-reported health indicators seem to be more appropriate and more efficient in surveys of health status in adolescence than health indicators based on medical records or medical statistics.

At present, a great deal of attention is focused in international journals on the health of adolescents, especially in Western Europe, but there is a lack of information about the health status of Slovak adolescents. Moreover, self-reported health indicators are very rarely used in research carried out on the Slovak population. This means we know very little about the health of Slovak adolescents, especially about self-reported health problems.

There is more than one reason why attention should be focused on this period of human life and on a Central European country.

Reprint requests and correspondence should be addressed to Andrea Geckova, Faculty of Science, Department of Humanities, Kossu Shoppera 22, 04801 Roznava, Slovak Republic. (E-mail: geckova@kosice.upjs.sk) 
Firstly, Member States of the World Health Organisation (WHO) in the European Region have adopted a strategy of Health For All (HFA) (1990). Its first "target" is focussed on reducing the health differences between countries and between groups within countries. Firstly however, we have to know how healthy Slovaks are and if there are any health differences between them and other member states. The findings of Ginter (1995, 1996) show poor health within the Central European population, particularly amongst the Slovak population. This is particularly apparent when compared with reported health statistics within the West European population. Is this also the case in the next generationadolescents?

Secondly, surveys of health should be a sufficient basis for health policy, but should also provide inputs for subsequent surveys to investigate socio-economic inequalities in health. Socio-economic differences are present to some extent during adolescence, but they increase in early adulthood. Longitudinal research may shed more light on the origin of socioeconomic health differences and on the possibilities of slowing the unwanted increase in these differences.

Thirdly, it is frequently accepted that it is better to protect health than to cure disease. Adolescence especially is the period of human life in which the basis of health-protective behaviour is established and the first symptoms of future serious health problems can occur.

Our study is part of an international comparative longitudinal study "Comparing Social Patterns in Health between Western and Central Europe in Adolescence." The Netherlands, Scotland and Slovakia are participating. The aim of this study is to explore health and social patterns in health with regard to a specific period in life and also within an international context. The international character, particularly the Slovak participation, has established possibilities of discussing findings in a Central-West European context. This is important, particularly because Central European countries are organized in a different way and very little is known about the character and the size of socio-economic health differences in these countries. This Slovak study follows parts of the Scottish and Dutch studies.

Scottish participation in this project is based on "The Study of Youth and Health" (West, 1986) which is a part of "The West of Scotland Twenty-08 study" (MacIntyre, 1987; MacIntyre et al., 1989). It is longitudinal in design and involves a 20-year follow-up of three age cohorts, 15, 35 and 55 years as the baseline. The sample of adolescents consists of 1009 respondents from the Central Clydeside Conurbation (Glasgow City and 10 surrounding local government districts), mean age 15 years. Comparable indicators were used in a Dutch study "Health in Adolescence" which is part of the "Longitudinal Study into Social Inequality and Health from Adolescence to early Adulthood" (Tuinstra, 1998). Baseline data collection was performed in 1994/1995 in the northern part of the Netherlands $(n=2090$, mean age $16 \cdot 2$ years).

Finally, gender comparison of self reported health problems is reported. The importance of the "gender" perspective in studies of adolescent health is also highlighted by findings of Goodman et al. (1997) and Gijsbers van Wijk and Kolk (1997).

\section{Methods}

\section{Procedure and respondents}

Data was collected in September and October of 1998 as a part of an international comparative longitudinal study "Comparing Social Patterns in Health between Western and 
Central Europe in Adolescence”. The sample consists of 2616 first-grade students of 31 secondary schools located in Kosice $(52 \cdot 4 \%$ boys, $47 \cdot 6 \%$ girls, and mean age 15 years). This sample was stratified according to gender and type of secondary school; the proportions of the five educational levels of the regular Slovak school system were maintained. Individual schools were selected at random. We can consider our sample as representative of the Slovak adolescent population. Respondents completed the questionnaires at school, in their classrooms and under the guidance of the field workers. The response rate was $96.3 \%$; the non-response was due to illness and other types of absence. The average occurrence of missing values was $0.5 \%$.

\section{Measures of health}

The data was compiled from self-reported questionnaires, which included the following six measures of health.

Self-reported health was measured by asking the respondents to describe their health as excellent, very good, good, fairly good or bad. There are a number studies confirming the relationship between this scale, and mortality and morbidity (Appels et al., 1996).

Psychological health was measured by the Slovak version of a 12 -item version of the General Health Questionnaire (GHQ) (Goldberg and Williams, 1988). The GHQ is a self-reported questionnaire consisting of statements about aspects of well-being, such as worries, tension or sleeplessness. With each statement, the current status of the respondent over the past 4 weeks is compared with his or her normal status by one of four responses. Two methods of scoring are used, a Likert score (range 0-36) and a binary score (range 0-12) which permits the identification of "cases" or in other words, a level of symptomatology of potential clinical relevance. According to Banks (1983) study, a cut-off point of $2 / 3$ should be used as a criterion for cases in adolescence.

Two subscales of the Slovak version of the RAND-36 (Van der Zee and Sanderman, 1993) were used to measure vitality and mental health. The four items of the vitality scale focus on feelings of energy and fatigue. The scale of mental health has five items representing feelings of depression and irritation. The respondents were asked to evaluate their feelings over the past four weeks. The scores were transformed following the prescribed formula (range 0-100). A higher score indicates better health status.

Experienced health complaints were measured by the Slovak version of a shortened 13-item version of the VOEG (Jansen and Sikkel, 1981). This questionnaire shows a valid and reliable picture of the current health status, expressed in physical health complaints. In the Slovak version, five anchor scales were used to describe the frequency of suffering from the included health complaints during the last month. For dichotomization, the frequency "to suffer three times or more during the last month" was used as the cut-off point. Both the prevalence of 13 separate VOEG items and the sum score of the VOEG varying from 0-13 were investigated.

Chronic diseases were assessed by means of a questionnaire based on the "Health Interview Survey of the Dutch Central Bureau of Statistic" (CBS, 1994). This questionnaire was improved according to the results of a pilot study and accessible data about the prevalence of chronic diseases in adolescence (Sobotik et al., 1994). The questionnaire in the present study provides a selection of 14 chronic diseases which are the most prevalent in adolescence. The respondents were asked whether or not they had suffered from any of these chronic diseases for longer than 3 months. We investigated the prevalence of the individual chronic diseases and also the average number of used categories per person. 
The questionnaire on use of medical care was created specially for the purposes of this study and was based on the questionnaire used in the Dutch sample (Tuinstra, 1998). A set of questions investigated the prevalence of serious illnesses (surgery, hospitalization and other serious illnesses), injuries which required health service, visits to doctors and the use of prescribed and non-prescribed drugs.

Validity of the health indicators used was discussed by Geckova et al. (1998), Pudelsky et al. (1999) and Javorsky et al. (2000)

\section{Analysis}

The analyses were carried out using the statistical software package SPSS, version 7.5.2. Boys and girls were analysed separately and possible gender comparisons were drawn. The distribution of the health measurements between the male and female adolescents were tested by a t-test (sum score of GHQ-12, average scores of vitality and mental health scales; dichotomous variables) or a Chi-square test (other variables; categorical variables).

\section{Results}

\section{Self-reported health}

On average, adolescents consider their health as very good. Boys $(68 \cdot 9 \%)$ and girls $(55 \cdot 1 \%)$ consider their health mostly to be excellent or very good. Less than $5 \%$ of adolescents consider their health to be fairly good or bad.

There are significant differences between boys and girls in self-reported health. As Table 1 shows, boys evaluated their health more positively than girls.

\section{Psychological health}

A sizeable number of Slovak adolescents were detected as "cases" (a level of symptomatology of potential clinical relevance). The psychological health of $23.9 \%$ boys and $41 \cdot 3 \%$ girls was not satisfactory (cases) in Slovakia. More than half of the adolescents detected as cases $(48 \cdot 1 \%-79 \cdot 1 \%)$ had been feeling unhappy or depressed, had felt constantly under strain, had suffered sleep deprivation and felt they could not overcome their difficulties. These items of GHQ-12 seem to be significant for being identified as a case. The first three of them were also indicated in a Dutch study (Tuinstra, 1998). The mean score of GHQ-12 (Likert) was $9 \cdot 34$ in boys and 11.57 in girls.

There are significant differences between boys and girls in psychological health. The psychological health of boys was significantly $(p \leq 0.01)$ better when compared with girls in

Table 1 Self-reported health

\begin{tabular}{lccc}
\hline & Boys (\%) & Girls $(\%)$ & Significance \\
\hline Excellent & $29 \cdot 2$ & $18 \cdot 7$ & $*$ \\
Very good & $39 \cdot 6$ & $36 \cdot 4$ & \\
Good & $27 \cdot 1$ & $40 \cdot 1$ & \\
Fairly good & $3 \cdot 1$ & $4 \cdot 1$ & \\
Bad & $1 \cdot 0$ & $0 \cdot 7$ & \\
\hline
\end{tabular}

*Significance $p<0 \cdot 01$. 
both methods of scoring and evaluation. Girls scored higher in GHQ and they were also more frequently detected as a cases, and they scored significantly higher than boys in all items of the questionnaire.

\section{Vitality and mental health}

Slovak adolescents may be described as often being full of energy (vital) and rarely depressed or irritated. Girls have significantly $(p \leq 0.01)$ less favourable mean scores in vitality (boys $64 \cdot 2$, girls $57 \cdot 7$ ) and mental scales (boys $71 \cdot 1$, girls $64 \cdot 6$ ) in comparison with boys. Scores of vitality were lower than 60 in $37 \%$ of boys and $52 \%$ of girls and scores of mental health were lower than 60 in $35 \%$ of boys and $52 \%$ of girls.

\section{Physical health complaints}

Only $40 \%$ of the boys and $23 \%$ of the girls reported none of the listed complaints. A considerable number of adolescents reported two or more health complaints (boys $41 \cdot 6 \%$, girls $61 \cdot 7 \%$ ). Boys reported a mean of $1 \cdot 76$ health complaints and girls $2 \cdot 86$; the difference is significant.

Adolescents mostly suffer from headaches and backache and also get up feeling tired and listless. More than 15\% of the boys and 30\% of the girls had suffered three times or more during the last month from these complaints. Approximately half of the girls had felt tired three times or more during the last month.

Gender differences are demonstrated in more detail in Table 2. This table shows the patterns of statistically significant sex differences for 12 out of 13 symptoms reported. The prevalence of nine out of the above 12 health complaints among girls is twice as high as it is in boys.

\section{Chronic diseases}

In our study, 0.7 chronic diseases per male and 0.9 chronic diseases per female were recorded; the difference is significant. Approximately half of the adolescents $(43 \cdot 3 \%$ boys,

Table 2 Physical health complaints

\begin{tabular}{lcccc}
\hline Category & Boys (\%) & Girls $(\%)$ & $\mathrm{f} / \mathrm{m}$ & Significance \\
\hline Stomach feels full and bloated & $5 \cdot 3$ & $12 \cdot 1$ & $2 \cdot 28$ & $* *$ \\
Get short of breath easily & $10 \cdot 4$ & $12 \cdot 8$ & $1 \cdot 23$ & $*$ \\
Have pains in the chest or heart region & $5 \cdot 4$ & $11 \cdot 1$ & $2 \cdot 06$ & $* *$ \\
Bones and muscles ever ache & $16 \cdot 6$ & $19 \cdot 6$ & $1 \cdot 18$ & $*$ \\
Feel tired & $27 \cdot 1$ & $47 \cdot 6$ & $1 \cdot 76$ & $* *$ \\
Headache & $16 \cdot 2$ & $33 \cdot 9$ & $2 \cdot 09$ & $* *$ \\
Backache & $12 \cdot 6$ & $23 \cdot 9$ & $1 \cdot 90$ & $* *$ \\
Upset stomach & $3 \cdot 9$ & $4 \cdot 8$ & $1 \cdot 23$ & $* *$ \\
Feel dead legs & $6 \cdot 4$ & $10 \cdot 0$ & $1 \cdot 56$ & $* *$ \\
Get tired sooner & $13 \cdot 2$ & $21 \cdot 3$ & $1 \cdot 61$ & $* *$ \\
Feel dizzy & $6 \cdot 2$ & $14 \cdot 7$ & $2 \cdot 37$ & $* *$ \\
Feel listless & $22 \cdot 2$ & $35 \cdot 8$ & $1 \cdot 61$ & $* *$ \\
Get up feeling tired and unrest & $30 \cdot 7$ & $38 \cdot 8$ & $1 \cdot 26$ & $* *$ \\
Average number of used categories per person & $1 \cdot 76$ & $2 \cdot 86$ & & \\
\hline
\end{tabular}

\footnotetext{
$* *$ Significance $p<0.01$
}

* Significance $p<0.05$. 
Table 3 Chronic diseases

\begin{tabular}{|c|c|c|c|c|}
\hline Category & Boys (\%) & Girls (\%) & $\mathrm{f} / \mathrm{m}$ & Significance \\
\hline Asthma, COPD & $1 \cdot 0$ & $2 \cdot 2$ & $2 \cdot 2$ & * \\
\hline Inflammation of frontal sinus & $1 \cdot 3$ & $1 \cdot 8$ & $1 \cdot 39$ & \\
\hline Hay fever & $14 \cdot 6$ & $12 \cdot 4$ & $0 \cdot 85$ & \\
\hline Allergy & $11 \cdot 5$ & $14 \cdot 2$ & $1 \cdot 23$ & $*$ \\
\hline Chronic complaints of the back & $15 \cdot 0$ & $22 \cdot 5$ & $1 \cdot 5$ & $* *$ \\
\hline Rheumatoid arthritis & $1 \cdot 1$ & $2 \cdot 7$ & $2 \cdot 46$ & $* *$ \\
\hline Epilepsy & $0 \cdot 1$ & $0 \cdot 6$ & $6 \cdot 00$ & ** \\
\hline Migraine & $3 \cdot 0$ & $6 \cdot 7$ & $2 \cdot 23$ & ** \\
\hline Skin diseases, eczema & $7 \cdot 2$ & $11 \cdot 0$ & $1 \cdot 53$ & ** \\
\hline Haemophilia & $0 \cdot 3$ & $0 \cdot 3$ & $1 \cdot 00$ & \\
\hline Diabetes & $0 \cdot 4$ & $0 \cdot 6$ & $1 \cdot 5$ & \\
\hline Inflammation of the bladder & $0 \cdot 4$ & $1 \cdot 0$ & $2 \cdot 5$ & \\
\hline Hypertension & $4 \cdot 3$ & $3 \cdot 1$ & 0.72 & \\
\hline Ulcer & $0 \cdot 1$ & $1 \cdot 0$ & 10 & $* *$ \\
\hline Other & $5 \cdot 4$ & $8 \cdot 8$ & $1 \cdot 63$ & ** \\
\hline Average number of used categories per person & 0.65 & 0.89 & & $* *$ \\
\hline
\end{tabular}

**Significance $p<0.01$.

$*$ Significance $p<0 \cdot 05$.

$52 \cdot 6 \%$, girls) suffered from at least one chronic disease. As Table 3 demonstrates, a sizeable number of adolescents suffered from chronic complaints of the back, hay fever, allergy, skin diseases, eczema and migraine.

With the exception of hay fever, significantly more girls than boys suffered from all mentioned chronic diseases. Girls suffered from migraine twice as frequently as boys did.

\section{Use of medical care}

Less than $10 \%$ of the adolescents had experienced serious illness during the last year. Less than $20 \%$ of the adolescents had used prescribed drugs, and less than $30 \%$ had used nonprescribed drugs. Less than $30 \%$ of adolescents had been seriously injured during the last year. Approximately half of the adolescents had visited the doctor during the last 2 months.

According to the use of medical care we - at least partially - confirmed poorer health in boys in comparison with girls. As can be seen in Table 4, twice as many boys as girls had been seriously injured during the last year, and the difference is significant. On the other hand, girls visited doctors and used drugs significantly more often.

As depicted in Table 5, the most frequently used group of prescribed drugs seems to be antibiotics or chemotherapeutics, and the most frequently used group of non-prescribed drugs seems to be painkillers. Respiratory disease seems to be the main reason for recourse to medical services.

An interesting question is who advises these adolescents to use non-prescribed drugs. Parents had advised children to use drugs in half of the cases and a quarter of adolescents had decided to take them for themselves. In $10 \%$ of cases, it was someone else who had given the advice. Findings show that parents play a very important role in health behaviour in both direct (they were advisors) and indirect ways (self-medication is probably related to parents' norms and values). 
Table 4 Use of medical care

\begin{tabular}{lccc}
\hline Category & Boys (\%) & Girls (\%) & Significance \\
\hline Serious illness during last year & $7 \cdot 9$ & $8 \cdot 7$ & \\
Serious injury during last year & $35 \cdot 9$ & $18 \cdot 4$ & $* *$ \\
Visit of doctor during last two months & $44 \cdot 2$ & $51 \cdot 2$ & $* *$ \\
Prescribed drug use during last two weeks & $17 \cdot 2$ & $20 \cdot 8$ & $*$ \\
Not prescribed drug use during last two weeks & $20 \cdot 8$ & $33 \cdot 7$ & $* *$ \\
\hline
\end{tabular}

** Significance $p<0.01$.

* Significance $p<0.05$.

Table 5 Most frequently used prescribed and non-prescribed drugs and reason for use of medical care (in \% boys/girls)

Group of used prescribed drugs

- antibiotics or chemotherapeutics $(5 / 5)$

- supportive symptomatic treatments of Group of used non-prescribed drugs respiratory diseases $(3 / 4)$

- antihistaminic $(2 / 3)$

- painkillers $(8 / 20)$

- vitamins or minerals $(7 / 7)$

- vitamins or minerals $(2 / 3)$

- supportive symptomatic treatments of respiratory diseases $(4 / 5)$

- painkillers $(3 / 2)$

Reason for visiting a doctor

- medical check-up, examination or vaccination $(16 / 19)$

- respiratory diseases $(15 / 21)$
Reason for using prescribed drugs

- respiratory diseases $(10 / 14)$

- allergies $(1 / 2)$
Reason for using prescribed drugs

- respiratory diseases (9/12)

- headaches $(4 / 10)$

\section{Discussion}

Our findings indicate that in the Slovak population, as in other countries, adolescence is not such a healthy period in human life as it is often considered. On the other hand, the occurrence of self-reported health problems was similar or lower in comparison to West European adolescents, specifically Scottish and Dutch adolescents. In this section, a summary of similarities and differences in health between Central and Western European adolescents will be discussed along with gender differences in health.

More Slovak adolescents $(68 \cdot 9 \%$ boys, $55 \cdot 1 \%$ girls) evaluated their health as excellent or very good compared with Scottish $(57 \cdot 1 \%$ boys; $50 \cdot 6 \%$ girls) (West et al., 1990) and Dutch adolescents $(62 \cdot 1 \%$ boys; $43 \cdot 5 \%$ girls) (Tuinstra, 1998). King et al. (1996) also reported that more Slovak (40\% boys; 22\% girls) than Scottish (28\% boys; $9 \%$ girls) adolescents evaluated their health as very good. King et al. (1996) reported that the number of respondents who felt very healthy decreased with increasing age $(11,13,15$-year-old cohorts) in the Slovak population.

Boys evaluated their health more positively than girls, and a similar pattern of gender differences in self-rated health was reported in 24 European countries and Canada by King et al. (1996). West et al. (1990) and Glendinning et al. (1992) confirmed these findings in Scottish adolescents and Tuinstra (1998) in Dutch adolescents. 
A similar percentage of Dutch $(22 \cdot 3 \%$ boys; $44 \cdot 4 \%$ girls) (Tuinstra, 1998) and a much lower percentage of Scottish (10.4\% boys; $18 \cdot 5 \%$ girls) (West et al., 1990) adolescents were indicated as a cases (psychological health on the level of potential clinical relevance). Our findings about the vitality and the mental health of Slovak adolescents are similar to Dutch findings (vitality: 62.57 boys; 54.25 girls; mental health: 72.10 boys; $64 \cdot 14$ girls) (Tuinstra, 1998).

Significant gender differences in psychological health, vitality and mental health were confirmed using the same questionnaire in Dutch adolescents (Tuinstra, 1998) and, in the case of psychological health, also in Scottish adolescents (West et al., 1990; Glendinning et al., 1992). Dzuka et al. (1993), Dzuka (1994) and Geckova (1999) used a different questionnaire of well-being (Bern Questionnaire for Psychological Well-being) (Dzuka et al., 1993; Dzuka, 1994) and confirmed gender differences in favour of boys.

Dutch adolescents (Tuinstra, 1998) reported more health complaints (boys 3.02; girls 4.62) than Slovak adolescents. The three most prevalent physical health complaints in the Slovak adolescent population were tiredness, headaches and backache, and were also most prevalent in the Dutch adolescent population (Tuinstra, 1998). According to King et al. (1996), only in Canada and Belgium is the prevalence of backache higher than in Slovakia ( $22 \%$ boys, $30 \%$ girls). If we consider that feeling listless - one of the most prevalent physical health complaints - may be interpreted as suffering from bad temper or being irritable, then the high prevalence of listlessness and backache appear to be something specific in Slovak adolescents. In Slovakia, the prevalence (suffered once or more a week during the previous 6 months) of bad temper ( $62 \%$ boys, $74 \%$ girls) and irritability ( $57 \%$ boys, $73 \%$ girls) was the highest among the 24 investigated European countries and Canada (King et al., 1996).

A sizeable number of Slovak adolescents, but also Dutch adolescents (32.8\% boys; $43 \cdot 3 \%$ girls) (Tuinstra, 1998) suffered at least one chronic disease. In Dutch adolescents, the prevalence of hay fever in both sexes and skin diseases and eczema in girls was higher than 10\% (Tuinstra, 1998), as it was in Slovak adolescents. Considerably more Slovak adolescents suffered from back complaints and less from asthma and chronic occlusive pulmonary disease (COPD) in comparison with Dutch adolescents. The prevalence of asthma and COPD was lower than 2\% in Slovak adolescents. According to Sobotik et al. (1994) the prevalence of COPD in the appropriate age group (14-24 years old) is $3 \cdot 3 \%$ in males and $0 \cdot 7 \%$ in females, and these figures are very similar to our findings. Because of a great deal of similarity between Czechs and Slovaks and their until recently unified history, we can use his data about the Czech population as approximate for the Slovak adolescent population. This approximation is also interesting because this data was based on physicians' records and equivalent data about the Slovak population at this age is not available. Sobotik found 0.77 chronic diseases per male and $0 \cdot 78$ chronic diseases per female was recorded in the age group 14-24 years old. These are very similar to the findings of our study. It would seem that our subjective health indicators could be considered as good indicators in comparison with objective health indicators. Both data based on self-reported questionnaires and data based on physicians' records confirm dorsopathies (as chronic diseases including chronic complaints of the back) and skin diseases as chronic diseases with the highest prevalence. It is also noteworthy that dorsopathies maintained the highest positions also in the next age group (25-34 years), in which the prevalence was more than double in comparison with younger age groups. Both sets of data also confirm a higher prevalence of chronic diseases in females then males.

Significantly more girls than boys suffered from almost all single physical health complaints and chronic diseases as seen in the Dutch adolescent population (Tuinstra, 1998). On the 
basis of an identical sample, Pudelsky et al. (2000) confirmed that adolescents suffering from at least one chronic disease evaluate their health less positively when compared with their healthy peers and also used medical services, particularly visited a doctor and used medication, more frequently than their healthy peers. Suffering from at least one chronic disease is accompanied by wider-ranging health consequences in adolescence.

Slovak adolescents are characterized by low use of medical drugs in comparison with other European countries (King et al., 1996). Only 12\% boys and 22\% girls used medical drugs for headaches, only $9 \%$ boys and $21 \%$ girls used them for stomach-aches, the same number for sleep problems and 33\% boys and 34\% girls for coughs or colds (King et al., 1996). This data is only partially comparable with our data, because King et al. did not differentiate between prescribed and non-prescribed drugs. Unfortunately, we do not have any comparable Dutch or Scottish data available.

Gender differences in use of medical care are not so homogeneous. Boys more frequently engage in risky behaviour and also in sporting activities which can lead to more injuries in comparison with girls. Conversely, girls more frequently report that they suffer from health complaints. This means they use medical services more frequently. Our findings, as well as the findings of Dengler and Roberts (1996) support this hypothesis. They examined the consumption of prescribed drugs and non-prescribed drugs by adolescents and found girls to be more frequent users in comparison with boys, particularly of prescribed drugs, nonprescribed painkillers or cough and cold treatments (Dengler and Roberts, 1996). But there are also some findings which show that, although girls tend to suffer from health complaints more frequently than boys, there are no significant differences in utilization of medical services, particularly in frequency of consulting a physician (Settertobulte and Kolip, 1997). In other words, girls suffer more frequently, but they only seek medical aid as frequently as boys do.

Our findings can be concluded as follows:

(1) Adolescents are not so healthy as often supposed. Attention should be paid particularly to the following health problems: psychological health, tiredness, headaches, backache, skin diseases and respiratory diseases.

(2) The character of adolescent health problems would indicate undesirable health processes which may lead to serious health problems (e.g. chronic respiratory diseases, chronic diseases of musculo-skeletal system), but they are, in this period of life, still preventable, reversible or at least they could be influenced in a more favourable way.

(3) The prevalence of self-reported health problems in the Central European adolescent population seems to be similar to or lower than the West European adolescent population.

(4) Our findings, like those of many other studies, confirm poorer health in girls in comparison with boys.

\section{References}

Appels, A., Bosma, H., Grabauskas, V., Gostautas, A. and Sturmans, F. (1996). Self-Rated Health and Mortality in a Lithuanian and Dutch Population. Social Science and Medicine, 5, 681-689. 
Banks, M. H. (1983). Validation of the GHQ in a young community sample. Psychological Medicine, 13, $349-353$.

CBS. Centraal Bureau voor de Statistiek, Langdurige aandoeningen bij de bevolking 1991, 1992 (1994). Vademecum Gezondheidsstatistiek Nederland.

Dengler, R. and Roberts, H. (1996). Adolescents' use of prescribed drugs and over-the-counter preparations. Journal of Public Health Medicine, 4, 437-442.

Dzuka, J., Flammer, A., Grob, A. and Neunschwnader, M. (1993). Vyskum psychickej pohody u slovenskych a svajciarskych adolescentov pomocou Bernskeho dotaznika psychickej pohody (BDP) - vysledky predvyskumu. (Research of psychological well being in Slovak and Swiss adolescents: Bern Questionnaire for psychological well-being pre-research results). Psychologia a patopsychologia dietata, 4, 309-322.

Dzuka, J. (1994). Subjektívna pohoda u slovenskej a rakuskej mladže (Subjective well being in Slovak and Austrian youth). Ceskoslovenska psychologie, 3, 193-205.

Geckova, A., Pudelsky, M., Katreniakova, Z., Nagyova, I., van Dalen, E. and Kovarova, M. (1998). Interpohlavne rozdiely subjektivnej pohody $\mathrm{v}$ adolescentnom veku (Intersexual differences in subjective well-being in adolescent age). Ceskoslovenska pediatria, 10, 623-627.

Gecková, A. (1999). Výchovne problémové správanie, rodinné prostredie a subjektívna pohoda adolescentov (Problematic behaviour, family background and well-being of adolescents). Psychológie a patopsychológia diet'at'a, 1, 13-20.

Gijsbers van Wijk, C. M. T. and Kolk, A. M. (1997). Sex Differences in Physical Symptoms: the Contribution of Symptom Perception Theory. Social Science and Medicine, 2, 231-246.

Ginter, E. (1995). Zdravotni stav Evropy a jeho projekce do roku 2000. I. Muzska populace (Health status in Europe and its Projection to the Year 2000. II. Male Population) Casopis lekane ceskych, 9, 265-269.

Ginter, E. (1996). Zdravotni stav Evropy a jeho projekce do roku 2000. II. Zenska populace (Health status in Europe and its Projection to the Year 2000. II. Female Population) Cas. lek. ces., 1, 3-7.

Glendinning, A., Love, J. G., Hendry, L. B. and Shucksmith, J. (1992). Adolescence and Health Inequalities: extension to Macintyre and West. Social Science and Medicine, 5, 679-687.

Goldberg, D. and Williams, P. (1988). A User's Guide to the GHQ. Windsor: NFER-Nelson.

Goodman, E., Amick, B. C., Rezendes, M. O., Tarlow, A. R., Rogers, Wh. and Kagan J. (1997). Influences of Gender and Social Class on Adolescents' Perception of Health. Archives of Pediatry and Adolescent Medicine, 151, 899-904.

Jansen, M. E. and Sikkel, D. (1981). Verkorte versie van de VOEG — schaal. Gezondheid en Samenleving, 2, 78-82.

Javorsky, M., Gecková, A., Pudelský, M. and Kovarova, M. (2000). Rozdiely medzi subjektívnym a objektívnym hodnotením zdravia u adolescentov. Ceskoslovenska Pediatria, 1, 21-27.

King, A., Wold, B., Tudor-Smith, C. and Harrel, X. (1996). The Health of Youth-a Cross-National Survey, Developmental patterns of behaviours and attitudes. WHO Regional Publications. European Series No. 69.

MacIntyre, S. (1987). The West of Scotland Twenty-07: Health in the community: the Survey s Background and Rationale. MRC Medical Sociology Unit. Working Paper No. 7.

MacIntyre, S., Annandale, E., Ecob, R., Ford, G., Hunt, K., Jamieson, B., MacIver, S., West, P. and Wyke, S. (1989). The West of Scotland Twenty-07 Study: health in the community. In Readings for a New Public Health, (C. Martin and D. MacQueen, Ed.). p. 56, Edinburgh University Press.

Pudelsky, M., Geckova, A., Nagyova, I., Kovarova, M., van Dalen, E., Tuinstra, J. and Post, D. (1999) Indikatory zdravia u adolescentov-validizacna studia (Health Indicators in AdolescentValidation Study) Ceskoslovenska Pediatria, 10, 549-555.

Pudelsky, M., Geckova, A., Nagyova, I., Kovarova, M., Katreniakova, Z. and van Dalen, E. (2000). Vyskyt chronickych chorob, subjektivne hodnotenie zdravia a vyuzivanie zdravotnickych sluzieb v adolescentnej komunite (Occurence of Chronic Diseases, Self-Reported Health and Medical Consumption among Adolescents). Slovenský LEKÁR No. 1-2, 16-20.

Settertobulte, W. and Kolip, P. (1997). Gender-specific factors in the utilisation of medical services during adolescence. Journal of Adolescence, 20, 121-132.

Sobotík, Z., Skalská, H. and Trísková, J. (1994). Chronická nemocnost zjistena ve vzorku ceske populace v roke 1989 I. Prevalence v zavislosti na veku a pohlavi (Chronic Morbidity Assessed in a Czech Population Sample in 1989. I. Age- and Sex-conditioned Prevalence). Hygiena, 3, 172-180. 
Tuinstra, J. (1998). Health in Adolescence. An Empirical Study of Social Inequality in Health, Health Risk Behaviour and Decision Making Styles. Thesis. Rijksuniversiteit Groningen.

Van der Zee, K. and Sanderman, R. (1993). Het meten van de algemene gezondheidstoestand, RAND36. Een handleiding. $\mathrm{NCH}$, University of Groningen.

West, P. (1986). The West of Scotland Twenty-07 Study: the Study of Youth and Health. MRC Medical Sociology Unit, Working Paper No. 2.

West, P., Macintyre, S., Annandale, E. and Hunt, K. (1990). Social Class and Health in Youth: findings from the West of Scotland Twenty-07 Study. Social Science and Medicine, 6, 665-673.

WHO Targets for Health for All. (1990). WHO Regional Office for Europe, Copenhagen 1985. 